\title{
Research on Optimization for the Piston Pin and the Piston Pin Boss
}

\author{
Yanxia Wang ${ }^{*}$ and Hui Gao \\ School of Traffic and Vehicle Engineering, Shandong University of Technology, Zibo 255049, Shandong, China
}

\begin{abstract}
Due to the fatigue failure and the fracture injury occurs under the alternative mechanical loads, the optimal design of the piston pin and the piston pin boss is presented depending on the FEA static analysis. The optimization is carried out using the Genetic Algorithm (GA), and the piston noncircular pin hole is used to further reduce the stress concentration on the upper end of the piston pin seat.
\end{abstract}

Keywords: Genetic Algorithm (GA), piston pin, stress concentration, noncircular pin hole.

\section{INTRODUCTION}

While the engine developed quickly and engine performance improved greatly, the demand for engine parts is becoming higher and higher. As an important part in engine, piston endures the cyclic gas pressure and the inertial forces at work, and this working condition may cause the fatigue damage of piston, such as piston side wear, piston pin seat crack and so on. The investigations previous indicate that the greatest stress appears on the upper end of the piston pin seat and this stress concentration is one of the mainly reason for fatigue failure $[1,2]$. Due to the complicated working environment for the piston, on the one hand, the FEA for the piston became more difficult; on the other hand, though there have many methods which are put forward to apply optimal design, the optimal parameters is not easy to determine.

In this study, the piston is used in a large medium-speed gas engine new developed. In order to enhance the engine dynamic and economic, it is necessary for the piston to implement optimization. The mathematical model of optimization is established firstly, and the FEA is carried out by using the ANSYS software. The GA Toolbox in MATLAB software is used to implement optimization. Based on the analysis of optimal result, the stress concentrates on the upper end of piston pin seat has become smaller, which provides a better reference for redesign of piston.

\section{THE FEA OF THE PISTON PIN}

\subsection{Theoretical Foundation}

The piston pin is used to connect the piston and the connecting rods in the internal combustion engine, and the piston pin transfers gas pressure to the connecting rods. The rubbing pair is constituted by the piston pin and piston pin boss; the gas pressure will be delivered to the rubbing pair through the piston pin and piston pin boss, and then the piston pin may occur bending. So the piston and the piston pin should have enough stiffness which can endure the pres-

*Address correspondence to this author at the Shandong University of Technology, Zibo 255049, Shandong, China; Tel: +86-533-2782616(office), +86-15022634 (Mobile); Fax: +86-533-2786837;

E-mail: wangyx200@163.com,gh0033@163.com sure and the friction between contacting surfaces. In addition, as an important part in engine, the working condition of piston is directly related to the reliability and durability of engine. So it is important for the piston pin and the piston pin boss to carry out structural and optimal analysis which can provide reference for design of piston.

The piston pin and the piston pin boss are the greatest parts which endure the pressure at works, and the linear velocity is lower. So the specific pressure between the piston pin and the piston pin boss should be restricted. The formula can be expressed as,

$q=\frac{p_{z}-p_{j}}{2 d l_{p}}$

Where, $p_{z}$ is the maximum gas pressure; $p_{j}$ is the reciprocating inertia force; $d$ is the reciprocating inertia force; $l_{p}$ is the effective length of piston pin.

\subsection{The Finite Element Analysis}

In this work, due to the symmetry of structure, $1 / 4$ model of piston and piston pin are assembled in the Pro/E software, and then the 1/4 FEM is established using ANSYS software. The 3-D 20-node solid element SOLID95 is applied to mesh the whole structure, and 102470 nodes and 48839 elements are obtained. In addition, in order to obtain the better result, the contact pair which is important to carry out the research should be established between the piston pin and piston.

The contact is highly non-linear and need more computing power. In order to compute effectively, it is important to know the physical property and establish the reasonable model. In this study, the surface-surface contact is applied to the model.

The FEA of piston pin and piston is carried out by using the ANSYS software. The equivalent stress and the deformation of the piston pin are obtained respectively, as shown in the Fig. (1 and 2).

As shown in the Fig. (1), the maximum stress appears in the middle of pin inner diameter and the value of the stress is $157 \mathrm{MPa}$. As shown in the Fig. (2), the maximum deformation occurs on the inside of piston pin and the value of deformation is $0.837 \mathrm{~mm}$. 
The analysis of contact is carried out by using ANSYS workbench software, and the result is shown in the Fig. (3 and 4). It is correspond with the truth.

\section{THE MATHEMATICAL MODEL OF OPTIMIZA- TION}

Piston pin and piston pin seat may appear deformation at work, which usually causes crack on the upper end of piston pin seat, as shown in the Fig. (5a, b) respectively. Due to the deformation, the greatest stress concentration is caused on the upper end of piston pin seat, as shown in the Fig. (5c), the situation becomes more serious when the stiffness of the piston is not enough, and the crack generally appeared at the point A which may gradually extend and even cause splitting along the piston vertical.

The stress distribution on the piston pin seat mainly depends on the deformation of piston pin. Therefore, in order

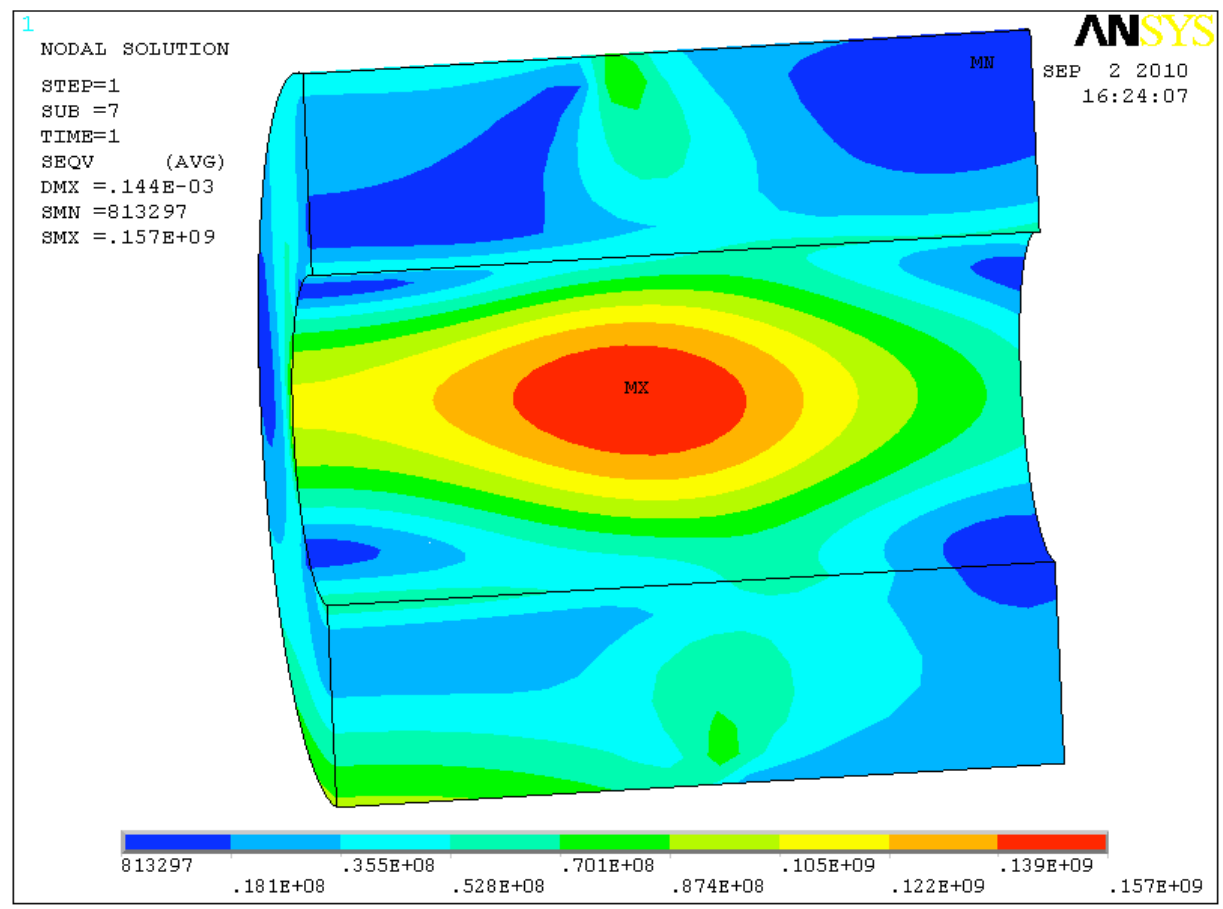

Fig. (1). The equivalent stress of piston pin.

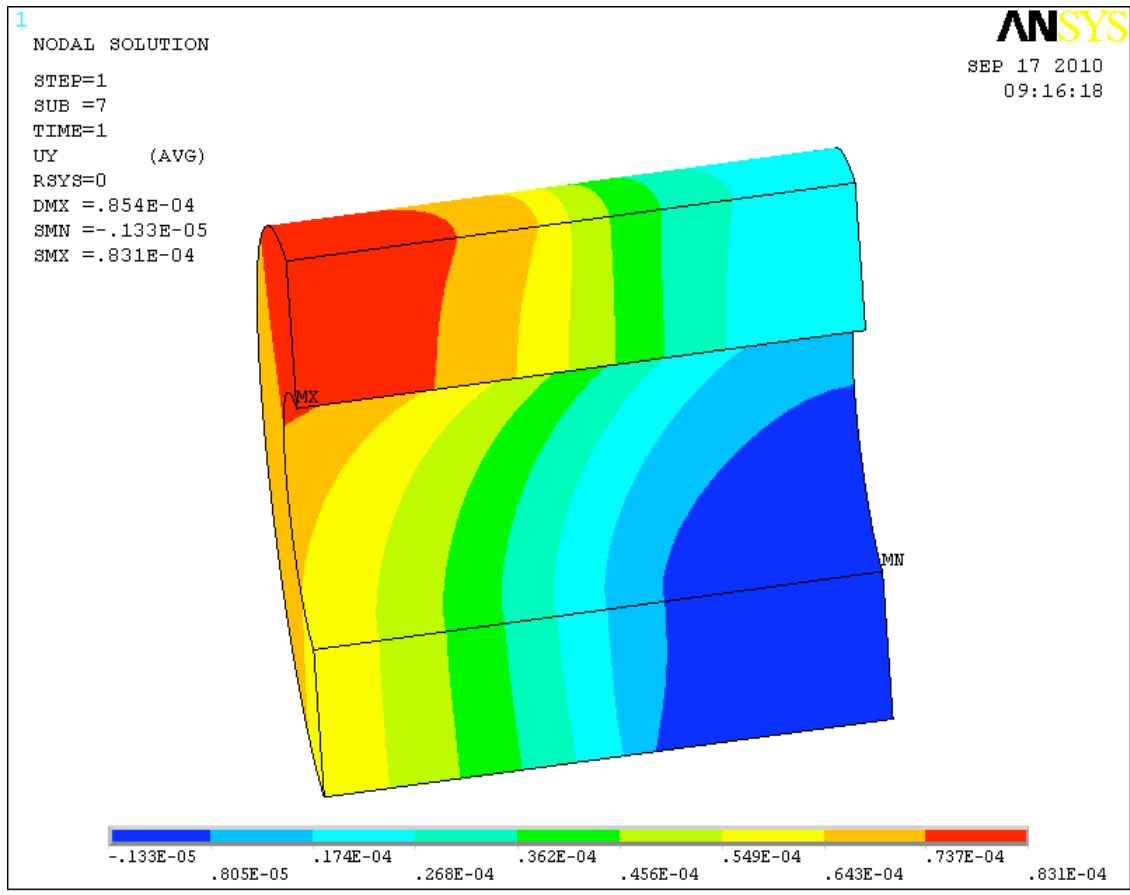

Fig. (2). The deformation of piston pin. 

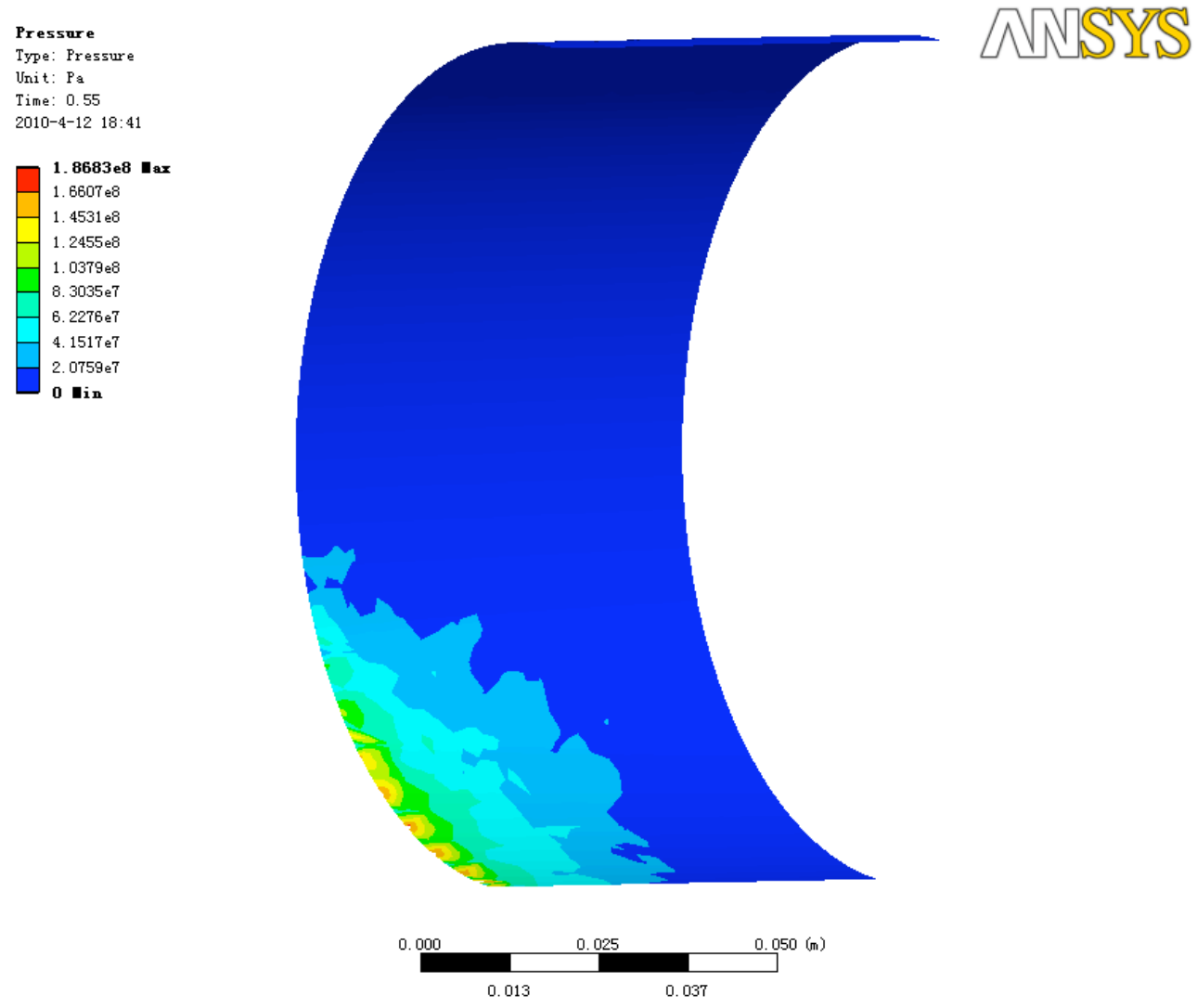

Fig. (3). The stress for the contact surface.
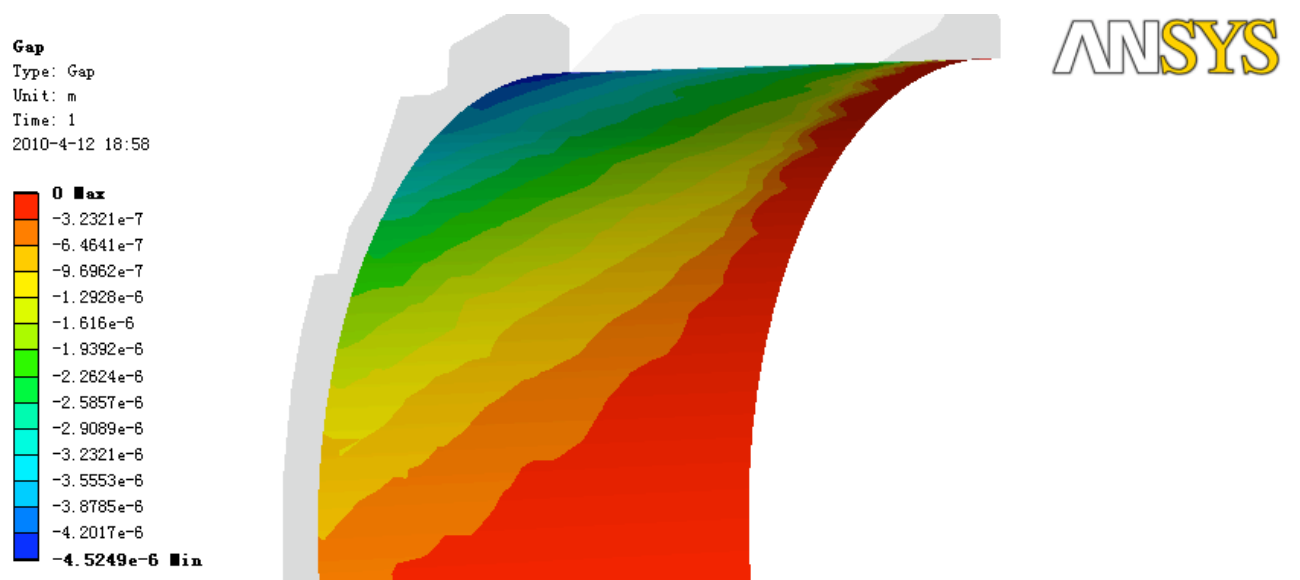

Fig. (4). The spaces between the contact surface. 


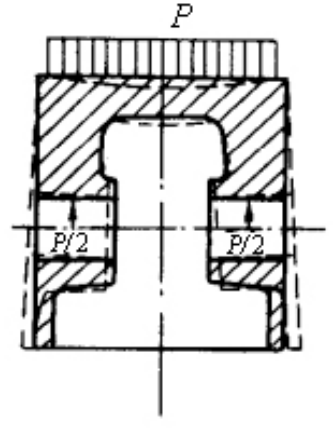

a

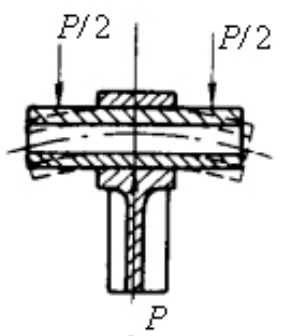

b

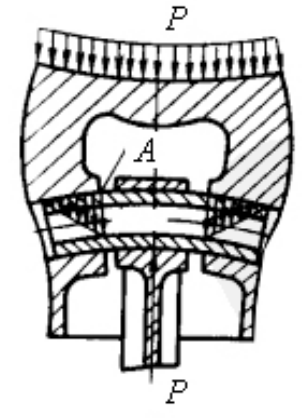

C

Fig. (5). The deformation sketch of piston pin and piston pin seat.

to reduce the stress concentration, the piston pin should have enough stiffness to reduce the deformation.

\subsection{Piston Pin Bending}

As the bending is calculated, the piston pin can be considered as a beam which is supported by two endpoints and is loaded in the middle, as shown in Fig. (6). According to the data given in the Fig. (6), the formula of piston pin bending [3] is given as:

$$
f_{1}=\frac{\left(p_{z}-p_{j}\right) D^{2}(l-2 c)^{2} l}{60 E\left(d^{4}-d_{0}^{4}\right)}
$$

Where, $l$ is the length of piston pin; $c$ is the half of the effective length of piston pin; $D$ is the piston diameter, $E$ is the elastic modulus; $p_{z}$ is the gas pressure; $p_{j}$ is the reciprocating inertia force.

\subsection{Piston Pin Elliptical Deformation}

The load on the piston pin is not only distributed along the axial, but also non-uniform distributed along the circumferential direction which is caused by the reacting force of piston pin seat and connecting rod. It is generally regarded as cosine distribution which leads to the piston pin elliptical deformation. The formula of elliptical deformation [3] is given as,

$$
f_{2}=\frac{\pi\left(p_{z}-p_{j}\right) D^{2}\left(d+d_{0}\right)^{3}}{320 E l\left(d-d_{0}\right)^{3}}
$$

\subsection{The Quality of Piston and Piston Pin}

The quality of the piston can be expressed as,

$W_{1}=c \rho_{1} \pi\left(r^{2}-d^{2}\right)$

And the quality of piston pin can be given as,

$$
W_{2}=l \rho_{2} \pi\left(d^{2}-d_{0}^{2}\right)
$$

Where $\rho_{1}$ is the density of the piston; $r$ is the outer radius of piston pin; $\rho_{2}$ is the density of the piston pin.

\subsection{The Mathematical Model of Optimization}

According to the above analysis, the multiple objective function is established to optimize the deformation of piston pin and the quality of piston. The objective function can be obtained from Eq. 2, to Eq. 5, and it is shown in the Eq. 6, as follows:

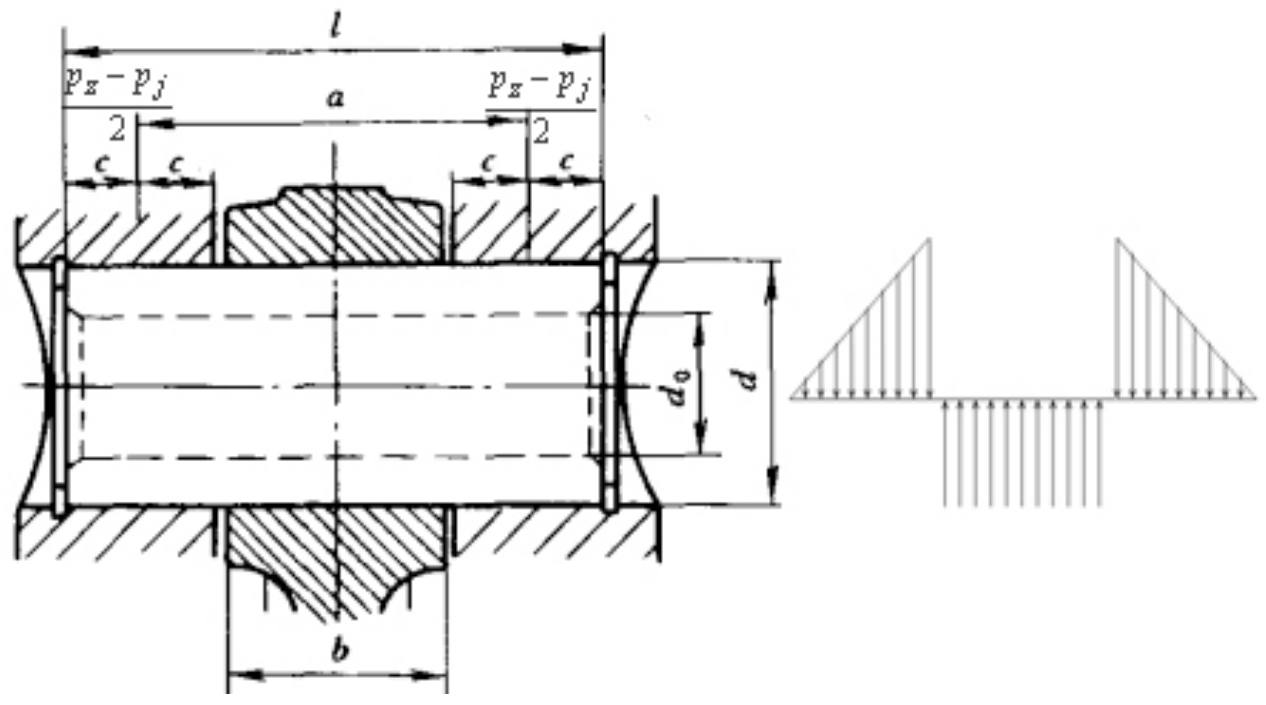

Fig. (6). The force sketch of the piston pin. 


$$
F=\omega_{1} f_{1}+\omega_{2} f_{2} / m_{1}+\omega_{3} W_{1} / m_{2}+\omega_{4} W_{2} / m_{3}
$$

Where, $w_{1}, w_{2}, w_{3}, w_{4}$ are weighting coefficient, $m_{1}, m_{2}, m_{3}$ are constant which is used to make the value of each objective to be at the same level.

Due to the complexity of piston group, the half of the effective length of piston pin $c$ and the inner diameter of piston pin $d_{0}$ are set as the design variable, and the other dimensions are defined as constant.

\section{OPTIMIZATION ALGORITHM}

GA is applied to solve the optimization problem in this study. The optimization is carried out by using GA Toolbox in MATLAB software. GA is very effective in some ways, such as function optimization, performance evaluation and so on, and the function optimization which is nonlinear, multi-model and multi-objective can obtain better results by using GA [4]. The flow chart of GA is expressed as the Fig. (7). According to the running procedures of GA, the main function is programmed by using the GA Toolbox [5] which is operated in MATLAB software.

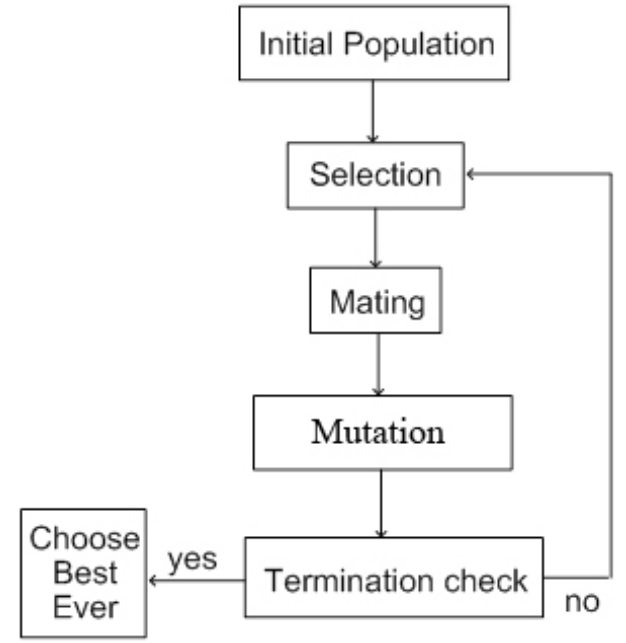

Fig. (7). The flow chart of GA.

The initial population distribution and the population distribution after 150 iterations are shown as Fig. (8a, 8b) respectively. The operation result indicated that the population distribution gathers at the convergence region after

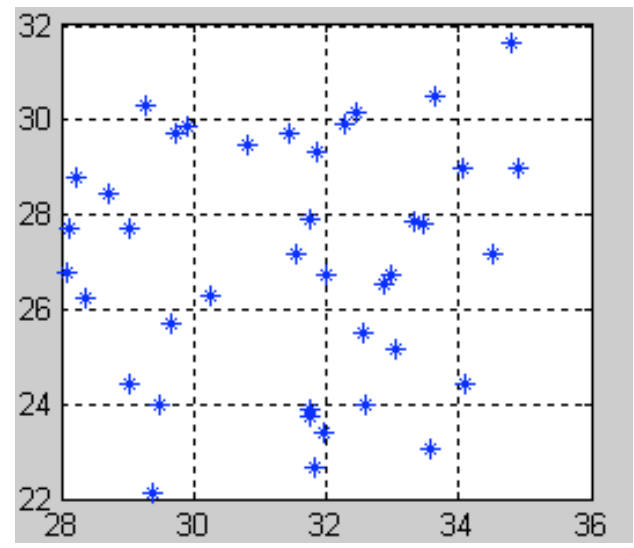

Fig. (8a). The initial population.

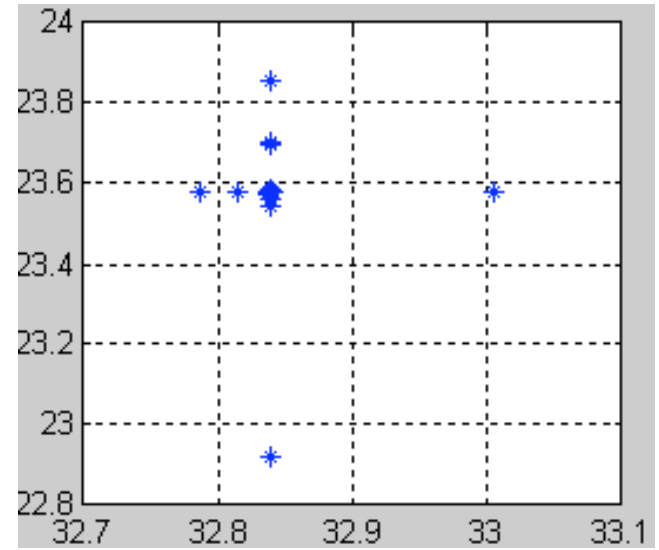

Fig. (8b). The population after 150 iterations.

150 iterations, and the optimal solution is $x_{0}=[32.8408$, 23.5886], that is the best values of the half of the effective length of piston pin $c$ and the inner diameter of piston pin $d_{0}$ are $32.8408 \mathrm{~mm}$ and $23.5886 \mathrm{~mm}$.

\section{NON-CYLINDER PISTON PIN HOLE}

On the basis of piston pin transmogrification, the noncylinder pin hole is applied to the piston so that the stress concentration on the upper end of piston pin seat can be further reduced. The non-cylinder pin hole is shown as the Fig. (9).

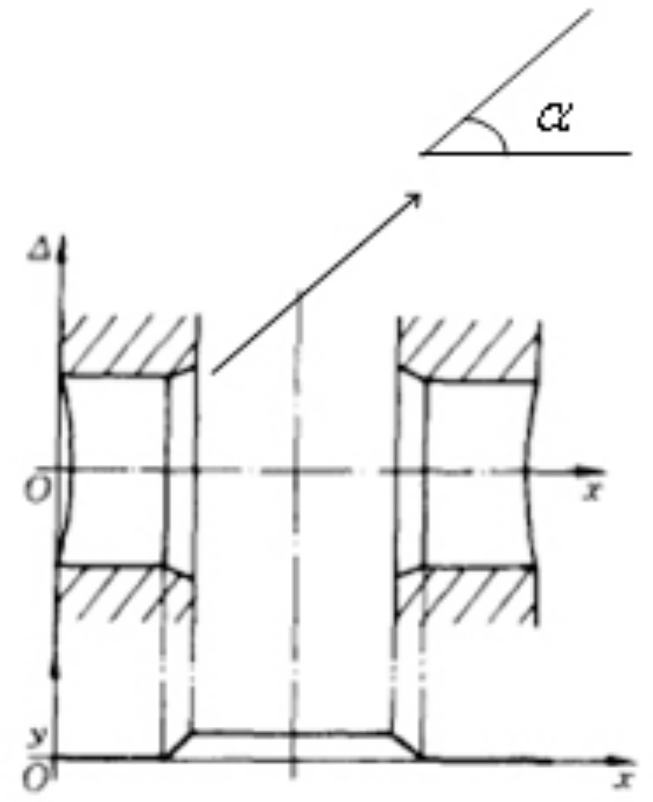

Fig. (9). The sketch of the non-cylinder pin hole.

\subsection{The Starting Point}

As shown in the Fig. (6), the contact length of the piston pin and piston pin seat is $l_{0}=2 c$. In general, the starting point for non-cylinder pin hole is located in 0.5-0.6 $l_{0}$ [6], and it is placed at the point of $0.55 l_{0}$ in this study. As known from the above optimization, the value of $l_{0}$ is $65.68 \mathrm{~mm}$, and the location of starting point is $36.14 \mathrm{~mm}$. 


\subsection{Taper Angle for Non-Cylinder Piston Pin Hole}

According to the FEA basing on the above solutions, the deformation values of piston pin from the starting point to end of piston pin seat are obtained and are shown in the Table 1. According to the Table 1, least squares curve-fitting is carried out by using MATLAB software, and the fitted regression equation is expressed as:

$y=0.0001 x^{2}+0.0021 x+0.8043$

The curve-fitting is shown in Fig. (10). Based on the curve-fitting equation, the taper angle [6] between curvefitting and horizontal direction is obtained and the value of the taper angle is $\alpha=0.2104^{\circ}$.

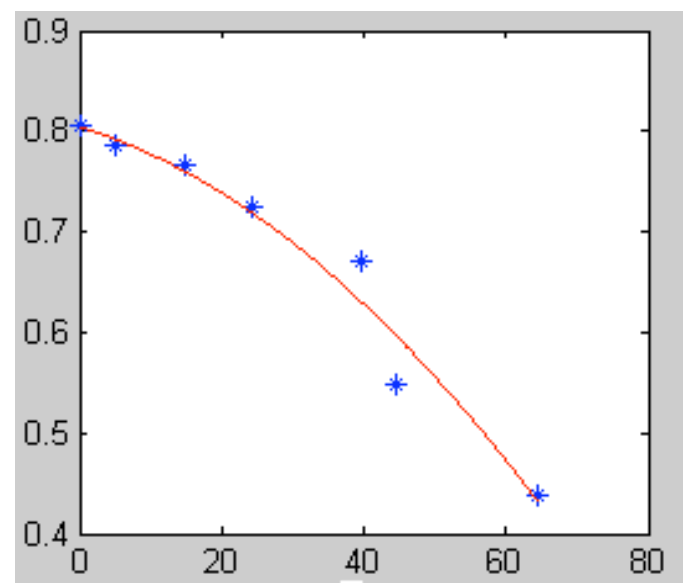

Fig. (10). The least squares curve-fitting.

\section{OPTIMIZATION ANALYSIS}

Compared with the initial piston model, the optimal piston mode is established which the values of the half of the effective length of piston pin $c$ and the inner diameter of piston pin $d_{0}$ have been changed from $28.00 \mathrm{~mm}$ and $27.00 \mathrm{~mm}$ to $32.8408 \mathrm{~mm}$ and $23.5886 \mathrm{~mm}$, the non-cylinder pin hole is applied to the optimal piston and the taper angle between curve-fitting and horizontal direction is $\alpha=0.2104^{\circ}$. For the initial model of piston and the optimal one, the FEA is carried out by using ANSYS software respectively. The distribution of equivalent stress is shown as Fig. (11a) and (11b). The maximum stress of two models occurs at the upper end of piston pin seat, and the value has changed from $171 \mathrm{MPa}$ to $145 \mathrm{MPa}$. The deformation of the piston is shown as Fig. (12a, 12b), and the biggest deformation of two models are generated at the skirt of the piston. The biggest deformation has changed from $0.359 \mathrm{~mm}$ to $0.301 \mathrm{~mm}$.

Table 1. The Deformation Values of Piston Pin

\begin{tabular}{|c|c|c|}
\hline No. & Coordinate (mm) & Deformation (mm) \\
\hline \hline 1 & 0 & 0.805 \\
\hline 2 & 4.93 & 0.785 \\
\hline 3 & 14.81 & 0.766 \\
\hline 4 & 24.15 & 0.724 \\
\hline 5 & 39.54 & 0.671 \\
\hline 6 & 44.53 & 0.548 \\
\hline 7 & 63.54 & 0.439 \\
\hline
\end{tabular}

\section{CONCLUSIONS}

1. The optimal mathematical model which includes the deformation of piston pin and the quality of piston

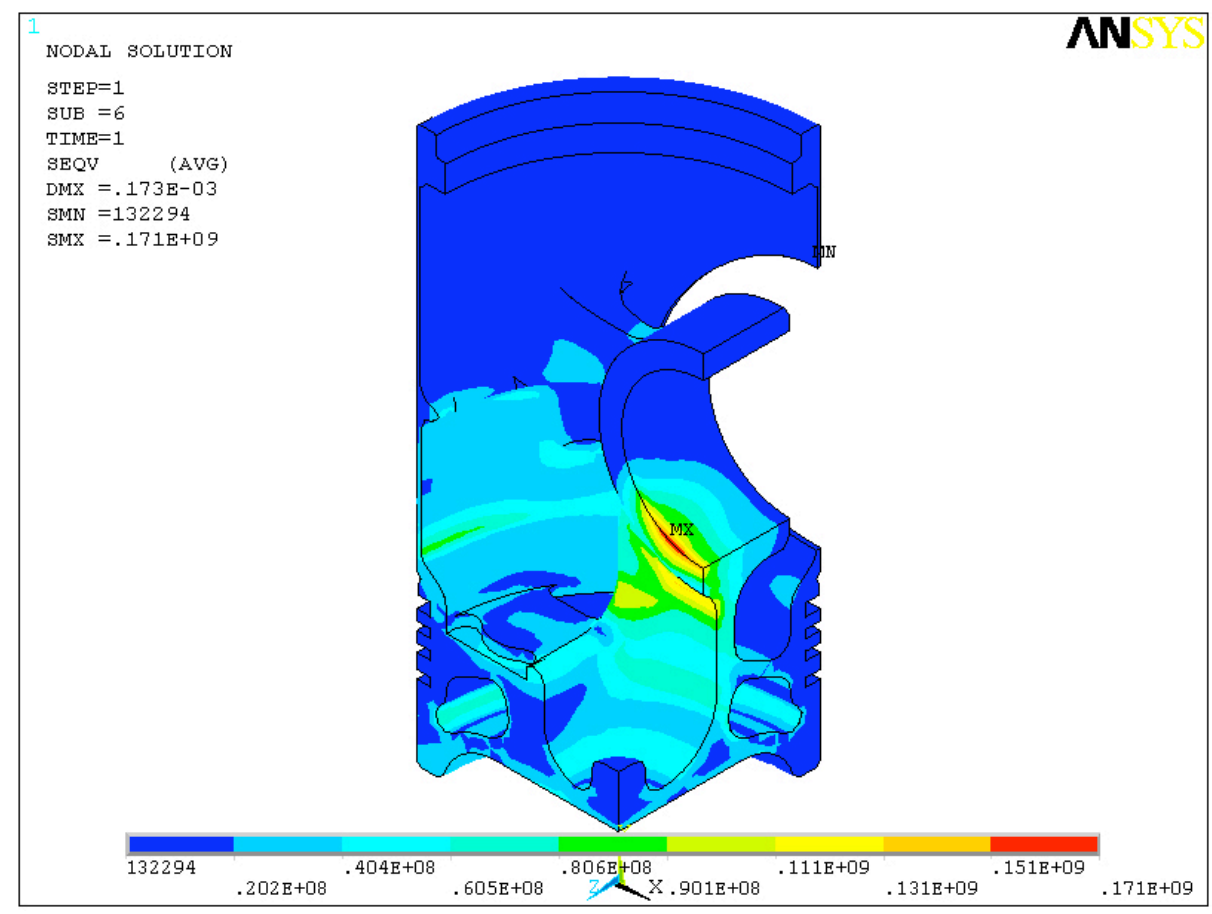

Fig. (11a). The distribution of equivalent stress of the initial model. 


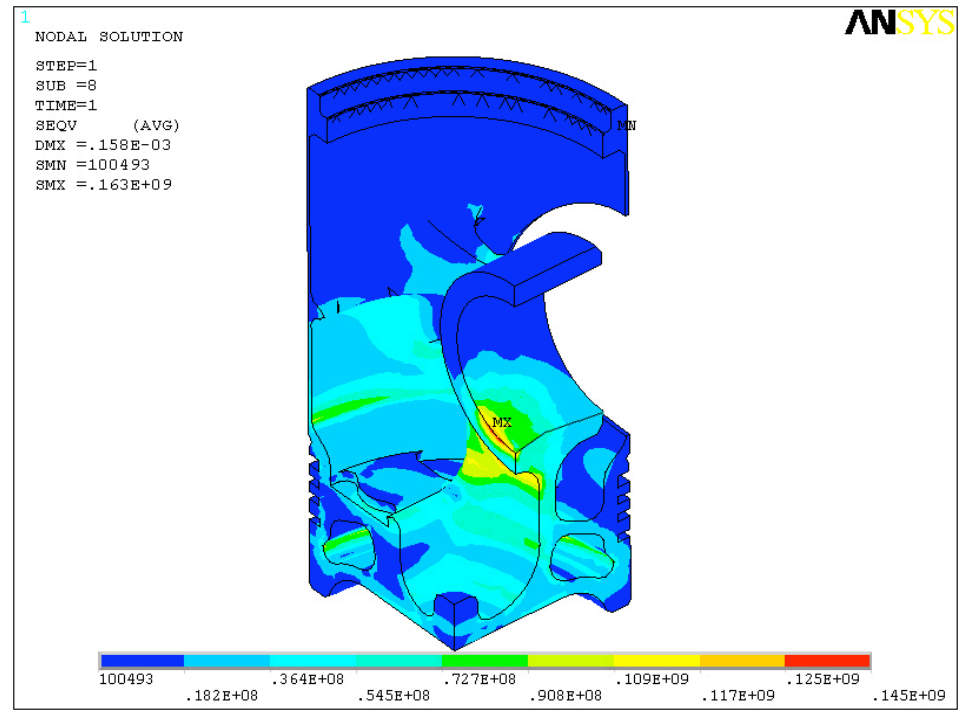

Fig. (11b). The distribution of equivalent stress of the optimal model.

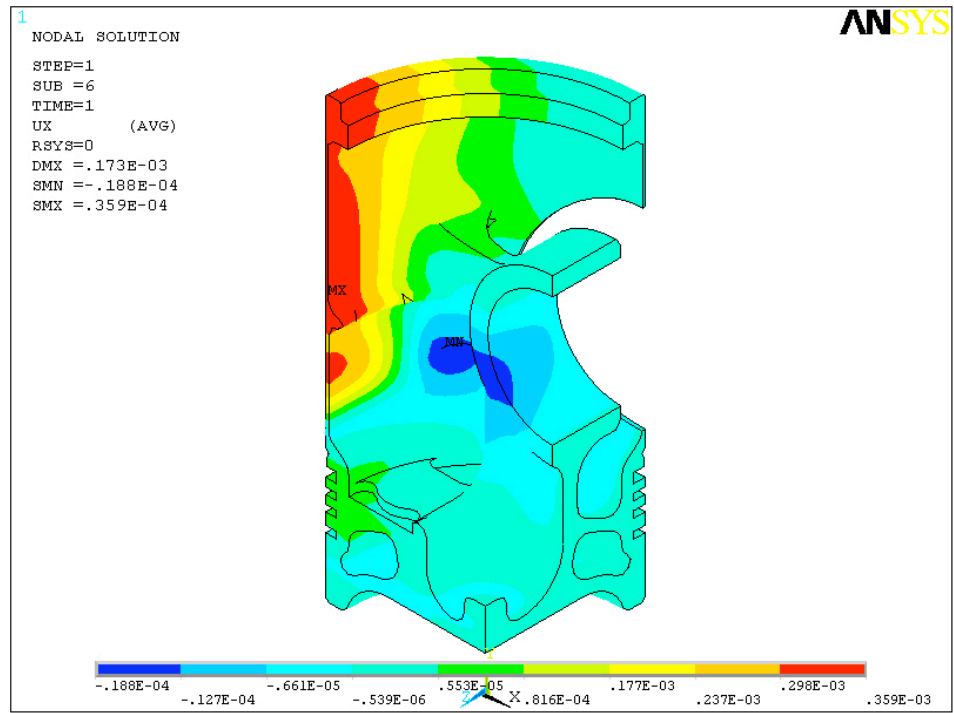

Fig. (12a). The deformation of the initial model.

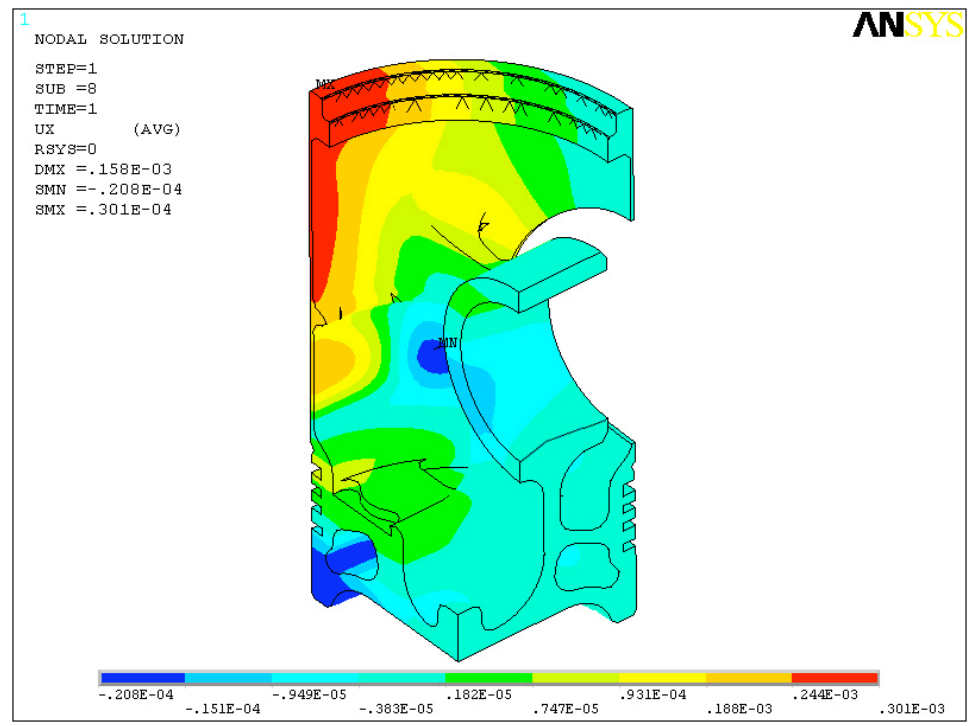

Fig. (12b). The deformation of the optimal model. 
and piston pin is established, and then the GA is applied to solve the problem. The optimization values of the effective length of piston pin $c$ and the inner diameter of piston pin $d_{0}$ are $65.6814 \mathrm{~mm}$ and $23.5886 \mathrm{~mm}$.

2. The non-cylinder pin hole is applied to the piston. The best taper between curve-fitting and horizontal direction is $\alpha=0.2104^{\circ}$.

3. The FEA is carried out for the initial piston model and the optimal one respectively. The results of analysis indicate that the maximum stress has changed from $171 \mathrm{MPa}$ to $145 \mathrm{MPa}$, and the biggest deformation has been reduced from $0.359 \mathrm{~mm}$ to $0.301 \mathrm{~mm}$

\section{ACKNOWLEDGEMENTS}

This project is supported by the University science and technology Program of Shandong Province of China (No. J10LD62) and the Nature Science Foundation of Shandong Province (No. ZR2010EM070).

\section{CONFLICT OF INTEREST}

None declared.

\section{REFERENCES}

[1] Y.Q. Liu, Y.X. Wang, X.H. Men, and F.H. Lin, “An Investigation on Piston Pin Seat Fatigue Life on the Mechanical Fatigue Experiments", Key Engineering Materials, vol. 25, pp. 527-531, 2006.

[2] L. Shi-Ying, L. Feng-Hua, Q. You-Zhi, and W. Zhi-Ming, "Piston Durability Research Based on the Pin-bore Profile Design", Chinese Internal Combustion Engine Engineering, Vol. 28, pp. 4650, 2007.

[3] X. Wan, and D. Lin. Engine Design. TianJin University Press, China, 1989.

[4] L. Chen. Genetic Algorithm of mechanism optimization design. Machine Industry Press, China, 2006.

[5] Y. Lei. MATLAB GA Toolbox and Application. XI'AN Science and Technology University Press, Press, China, 2005.

[6] Y. Zheng. "The finite element design for non-cylinder hole of piston", Design and Manufacture of Diesel Engine, vol. 87, pp. 4449, 1999.

(C) Wang and Gao; Licensee Bentham Open.

This is an open access article licensed under the terms of the Creative Commons Attribution Non-Commercial License (http: //creativecommons.org/licenses/by$\mathrm{nc} / 3.0 /)$, which permits unrestricted, non-commercial use, distribution and reproduction in any medium, provided the work is properly cited. 